\title{
Correlation between constitutive heterochromatin and restriction enzyme resistant chromatin in Arcyptera tornosi (Orthoptera)
}

\author{
J. Gosálvez,* \\ J. L. Bella, \\ C. López-Fernández* and \\ R. Mezzanotte $\dagger$
}

\author{
* Dpto. de Genética C-XV, Facultad de Ciencias, \\ Universidad Autónoma de Madrid, Madrid 28049, \\ Spain and \\ † Istituto di Biologia Generale, Facolta di Medicina e \\ Chirurgia, Via Ospedale 119, 09100 Cagliari, Italy.
}

Fixed mitotic chromosomes of $\boldsymbol{A}$. tornosi have been analysed by means of C-banding, DA-DAPI and Chromomicin $\mathrm{A}_{3}$ fluorescence, as well as by digestion in situ with Alu I, Hae III, Hinf I and Hind III restriction endonucleases. From the results obtained at least nine types of chromatin can be distinguished in $A$. tornosi. Some $C$-band positive areas (constitutive heterochromatin) which show a characteristic fluorescence pattern are digested by specific endonucleases, whilst others are undigested. C-band negative areas (euchromatin) are digested by some restriction endonucleases but not by others. Regions digested are supposed to contain highly repetitive DNAs. It is noteworthy, however, that the heterochromatin associated with NORs is not attacked by any of the enzymes we used, while regions believed to contain AT-rich DNA (DA-DAPI positive) are digested by Hae III that cleaves the GG $\downarrow$ CC base sequence target.

\section{INTRODUCTION}

The study of metaphase subchromosomal structural and functional organisation has been made possible by the discovery and the application of banding techniques in mitotic chromosomes (MacGregor and Varley, 1983). C-banding is a method routinely used for localising constitutive heterochromatin in a number of organisms (Sumner, 1972; King and John, 1980). The use of DNA specific fluorochromes such as $4^{\prime}-6$ diamidino-2phenylindole (DAPI) or chromomicin $\mathrm{A}_{3}\left(\mathrm{CMA}_{3}\right)$ which permit the detection of chromosomal regions containing high amounts of AT- or GCbase pairs respectively are particularly important. (Schweizer, 1976; Jorgenson et al., 1978; Schweizer, 1981). Moreover, such DNA base specific compounds allow the detection of different classes of heterochromatin by producing different fluorescent responses in regions previously believed homogeneous from C-banding (John et al., 1985).

Several classes of chromatin, differing in terms of DNA base composition, may also be detected by the use of certain restriction endonucleases (RE) which differentially digest the DNA localised in different chromosomal regions and give rise to specific and reliable banding patterns (Mezzanotte et al., 1983a, b; Miller et al., 1983; Kaelbling et al., 1984; Bianchi et al., 1985; De Stefano et al., 1986; Mezzanotte, 1986). As C-band material is presumed to often contain highly repetitive DNA, specific C-band regions should be extensively digested or, alternatively, completely unaffected, when their presumed repetitive DNAs contain or lack respectively the target of a given RE.

It is also possible that repeated base sequences are localised in areas not considered to be constitutive heterochromatin. If such base sequences do not contain the target of a specific RE they will remain undigested and thus should stain differentially.

In order to investigate the structure and distribution of such heterochromatic regions we used specific DNA fluorochromes and specific restriction endonucleases to probe the chromosome complement of the grasshopper Arcyptera tornosi.

\section{MATERIAL AND METHODS}

Mitotic chromosomes of Arcyptera tornosi were obtained from ovariole tips and gastric caeca. Females were intrabdominally injected with 0.05 per cent colchicine in insect saline solution 6 hours prior to dissection. Standard fixation in 
ethanol:acetic acid $(3: 1)$ was carried out. Meiotic chromosomes were obtained from males. Testes were removed and fixed in ethanol:acetic acid $(3: 1)$.

In all cases tissues were squashed in a drop of 45 per cent acetic acid. The coverslip was removed with a razor blade after immersing the slides in liquid nitrogen and then air dried. Fluorescence patterns were analysed by using the methodology developed by Schweizer $(1976,1980)$ with minor modifications (Schweizer, personal communication). Photographs of $\mathrm{CMA}_{3}$ and DA-DAPI were taken on Valca 125 ASA film using a ZEISS photomicroscope.

Digestion with Alu I, Hae III, Hind III or Hinf I restriction endonucleases was performed in all cases on fresh dried preparations (no more than 6 hours after removing the coverslip). Enzyme solutions were prepared according to Mezzanotte (1986). The solution on the slide was covered with a coverslip to spread the enzyme evenly. Incubation was carried out overnight at $37^{\circ} \mathrm{C}$ in a moist chamber. Control experiments were performed under identical conditions by treating cytological preparations with the incubation buffer without the enzyme.

Incubation was stopped by washing the slides in a solution containing $10 \mathrm{mM}$ tris $-\mathrm{HCl}$ and $5 \mathrm{mM}$ EDTA, $p \mathrm{H} 7 \cdot 0$. Staining was performed with either 2 per cent Giemsa (in buffer phosphate $p$ H 6.8) or Acridine Orange (Bella et al., 1986).

\section{RESULTS}

\section{Heterochromatin characterisation}

Arcyptera tornosi has the standard $2 n=22+X$ o, $22+X X$ \& chromosome complement comprising a graded series of uniarmed chromosomes $\left(\mathrm{L}_{1}-\mathrm{L}_{2}\right.$; $\mathrm{M}_{3}-\mathrm{M}_{9} ; \mathrm{S}_{10}-\mathrm{S}_{11}$; the $X$ is medium sized). C-banding reveals the presence of small centric bands in all chromosomes while only the autosomes $\mathbf{M}_{7}$ to $S_{11}$ show distal bands (fig. 1(a)). Those located on chromosomes $\mathrm{M}_{4}, \mathrm{~S}_{10}$ and $\mathrm{S}_{11}$ are particularly large and polymorphic (Gosálvez et al., 1981; LópezFernández et al., 1982; de la Torre et al., 1986). In some cases the paracentromeric C-bands of both $\mathrm{M}_{3}$ and $\mathrm{S}_{11}$ chromosome pairs differ in size between the homologous (fig. 1(a)).

Acridoid species possess a "megameric" chromosome pair which condenses precociously, may be multibanded and is the third smallest member. In $A$. tornosi, this chromosome is the $\mathrm{M}_{9}$. $C$-banding reveals the presence of two bands (bands 91 and 92) near the centromere, while two
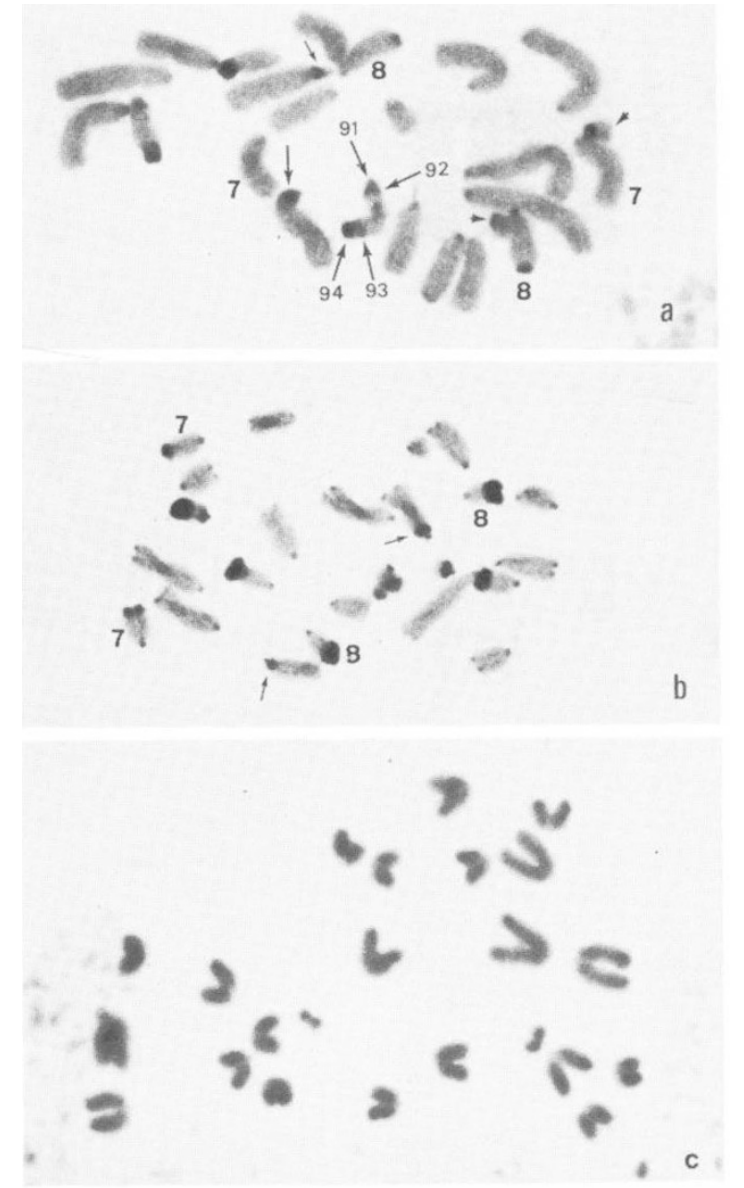

Figure 1 (a) C-banded metaphase in A. tornosi. Chromosomes $\mathbf{M}_{7}$ and $\mathbf{M}_{8}$ are marked to compare with fig. 1(b). The megameric chromosome $\left(\mathrm{M}_{9}\right)$ with four $\mathrm{C}$-positive bands and the nucleolar chromosome $\mathrm{M}_{3}$ are arrowed to compare the response of these regions with that obtained with other cytological treatments. Arrowheads indicate a heterozygous chromosome pair $\left(S_{11}\right)$ for paracentromeric bands. (b) Giemsa stained mitotic metaphase of $\boldsymbol{A}$. tornosi after digestion with Alu I. Note the large size of the distal segments in some chromosomes $\left(\mathbf{M}_{7}, \mathbf{M}_{8}\right)$ and the presence of darkly stained telomeres which are not C-banded (see lig. 1(a)) and do not show specific fluorescence (fig. 2(a), (b)). (c) Somatic metaphase of $A$. tornosi after digestion with Hind III and stained with Giemsa. No longitudinal differentiation is observed.

additional bands (bands 93 and 94), which are difficult to distinguish from each other, are located in the distal region of this chromosome (fig. 1(a)).

Silver staining, used to detect active nucleolar regions, shows that the main nucleoli are associated with the paracentromeric heterochromatin of the $\mathrm{M}_{3}$ and the distal heterochromatin (C-band 93) of the $M_{9}$ chromosomes (compare fig. 1(a) and 2(c)). The use of DNA specific fluorescent dyes furnishes detailed information on the different 

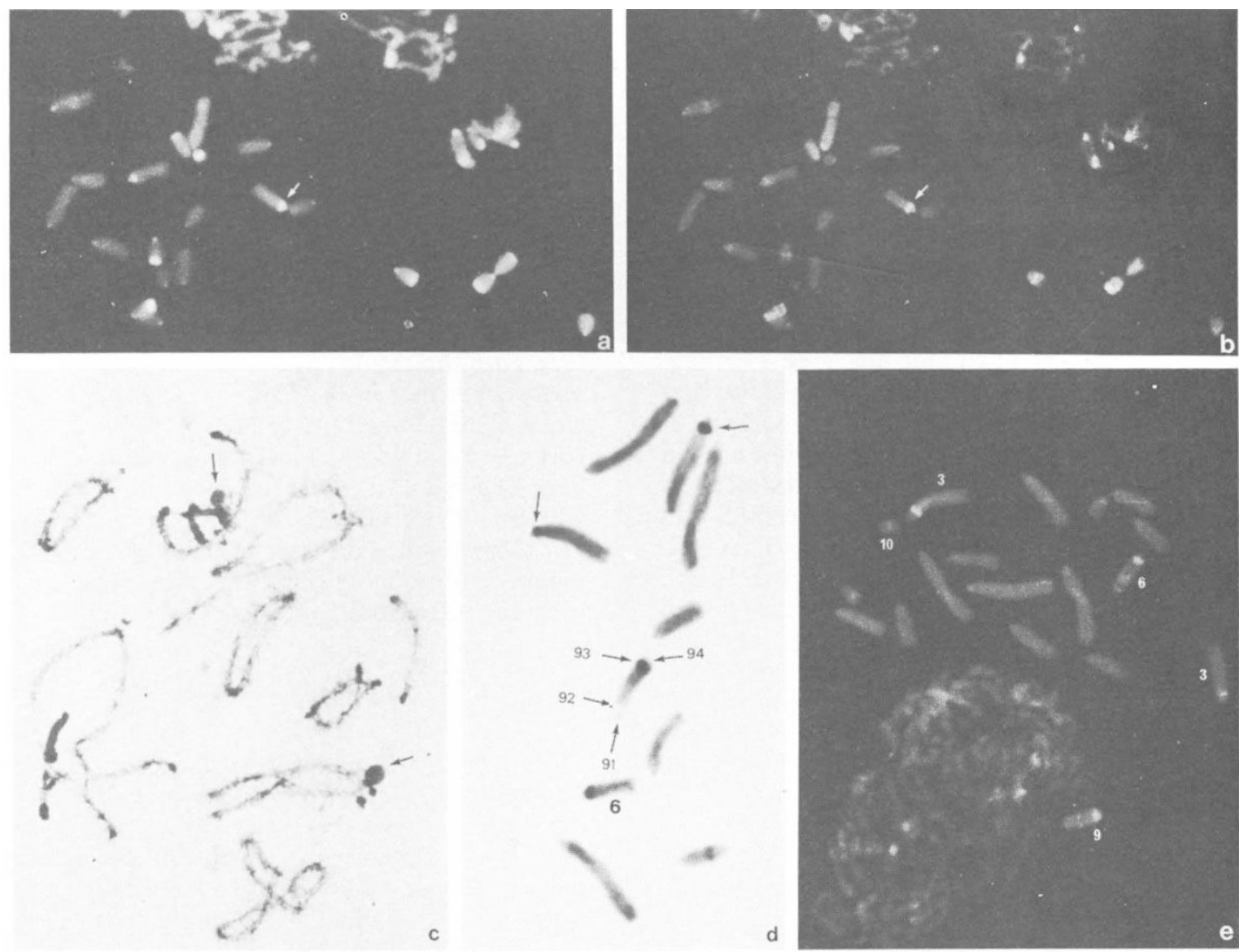

Figure 2 (a) Metaphase plate of $A$. tornosi tri-stained and excited to uncover DA-DAPI fluorescence. Distal and centromeric heterochromatin is DA-DAPI+. (b) Same plate excited to uncover CMA fluorescence; the arrow in (a) and (b) indicates the position of different types of heterochromatin associated with the NORs. (c) Silver staining of a diplotene cell showing that $\mathbf{M}_{3}$ and $\mathbf{M}_{9}$ (megameric) are the nucleolar chromosomes. (d) Metaphase chromosomes digested with Hae III and stained with Giemsa. Arrows indicate the heterochromatin associated with the NORs in chromosome $\mathbf{M}_{3}$. (e) Metaphase chromosomes stained with $\mathrm{CMA}_{3}$. Note bright fluorescence in a paracentric band of chromosome $\mathbf{M}_{3}$. Note that the undigested chromatin with Hae III is mostly $\mathrm{CMA}_{3}+$.

heterochromatic regions. DA/DAPI + fluorescence is present at the C-bands of the pericentromeric and the telomeric regions of every autosome (fig. 2(a), 5(b)).

In contrast $\mathrm{CMA}_{3}$ produces positive fluorescence only in the areas related to the nucleolar organiser regions on chromosomes $\mathbf{M}_{3}$ and $\mathbf{M}_{9}$ (fig. $2(\mathrm{~b}),(\mathrm{c})$ and $5(\mathrm{a}))$, in the paracentromeric region of chromosome $\mathbf{M}_{6}$ which is not C-banded (fig. 2(e)), in the C-band 92 of the megameric chromosome (fig. 5(a)) and in two very small interstitial dots in chromosome $\mathrm{S}_{10}$ (fig. 5(d)).

The heterochromatin associated with the NOR in chromosome $\mathbf{M}_{3}$ is formed by two very close regions of different structure: one, near the centromere, is DA-DAPI + , while the other is $\mathrm{CMA}_{3}+$.
This is detected only in tri-stained slides where sequential observation of both bands is possible (compare fig. 2(a) with 2(b)). The heterozygosity detected in the nucleolar chromosome $\mathrm{M}_{3}$ of some individuals is caused by a decrease in the size of both DA-DAPI + and $\mathrm{CMA}_{3}+$ bands which constitute the C-positive band. The nucleolar chromosome $\mathrm{M}_{9}$ also shows DA-DAPI + region related to the NOR which is close to the $\mathrm{CMA}_{3}+$ region (band 93); (see heterozygous half bivalent in fig. $5(\mathrm{~b}))$.

\section{Selective digestion with restriction enzymes}

The results obtained by staining the chromosomes with either Giemsa or Acridine Orange after RE 
digestion are identical. In both control slides and those treated with Hind III the chromosomes of A. tornosi fail to show appreciable longitudinal differentiation (fig. 1(c)). This agrees with the results obtained on human chromosomes (Miller et al., 1983). On the other hand, Alu I, Hinf I, and Hae III produce clearcut chromosome differentiation, which resembles that obtained by $\mathrm{C}$-banding but with some particular differences for each enzyme.

It is important to stress that in $\boldsymbol{A}$. tornosi as in some other species, restriction enzymes seem capable of cleaving the DNA located at specific sites regardless of the degree of chromatin packing. It is thus possible to observe the presence of undigested and intensely stained blocks in interphase or early prophase which correspond to specific regions of metaphase chromosomes (fig. 3 ). Alu I digestion induces bands whose length appears to include more material than the C-band positive material of the distal regions of chromosomes $\mathbf{M}_{7}$ to $S_{11}$ (compare fig. 1(a) and 1(b)). This is particularly clear in the case of the $M_{7}$ and $M_{8}$ pairs. The telomeres of these chromosomes, in fact, show very small C-bands, while revealing large undigested blocks after Alu I treatment. It is noteworthy that Alu I activity permitted the detection of small distal bands not observed using either C-banding, or specific fluorescent dyes, in long and medium chromosomes $\left(\mathrm{L}_{1}\right.$ to $\left.\mathrm{M}_{6}\right)$.

Hinf I produces a pattern similar to that obtained by Alu I treatment, with the exception that C-band 92 of the megameric chromosome is completely digested (fig. 4(a), (b)). Moreover, the telomeres of the long and medium chromosomes, unaffected by Alu I, are cleaved by Hinf I and thus faintly stained (fig. 4). Hae III shows a rather inconsistent behaviour as regards its capacity to digest certain heterochromatic regions revealed as C-bands in the karyotype of $A$. tornosi (see fig. 2(d)). Thus, both $\mathrm{C}$-bands of chromosomes $\mathrm{M}_{3}$ and $\mathrm{M}_{9}$ associated with nucleolar organisers appear unaffected after treatment with Hae III. However C-bands 91 and 94 are cleaved to the same extent as euchromatin and C-band 92 suffers greater digestion as revealed by the unstained gap observable near the centromere region of this chromosome. On the other hand, chromosome $\mathbf{M}_{6}$ exhibits a paracentromeric band which is not $\mathrm{C}$ banded but corresponds to a region not related to any active nucleolar organiser which is $\mathrm{CMA}_{3}+$ (compare fig $1(\mathrm{c}) ; 2(\mathrm{~d})$ and $2(\mathrm{e})$ ). It is also noteworthy that in the chromosome $\mathrm{S}_{10}$, Hae III cleaves the telomeric C-band that is DA/DAPI+, $\mathrm{CMA}_{3}-$, but does not affect the interstitial $\mathrm{CMA}_{3}+$ band (fig. 5(c), (d), (e)). It is difficult to ascertain whether or not these $\mathrm{CMA}_{3}+$ dots are related to any C-band since they are close to a DA-DAPI+ region and probably both fluorescent areas comprise the interstitial C-positive band.

\section{DISCUSSION}

The effects of RE digestion on fixed chromosomes may be explained by a consideration of the following factors: (a) the presence or absence of specific DNA base sequences in particular chromosome regions, (b) the ability of a given $\mathrm{RE}$ to cut a base sequence target, which may or may not be accessible depending on the organisation of specific chromosome regions, (c) the amount of RE activity on fixed chromosomes is also affected by the length of their specific targets.

The DNA fragments produced by the digestion with REs of $6 \mathrm{bp}$ targets should be longer than those resulting from the treatment with REs of 4 or $5 \mathrm{bp}$ targets, since the number of cleavage sites of the former is expected to be lower than that of the latter. As a consequence, it is believed that 4-5
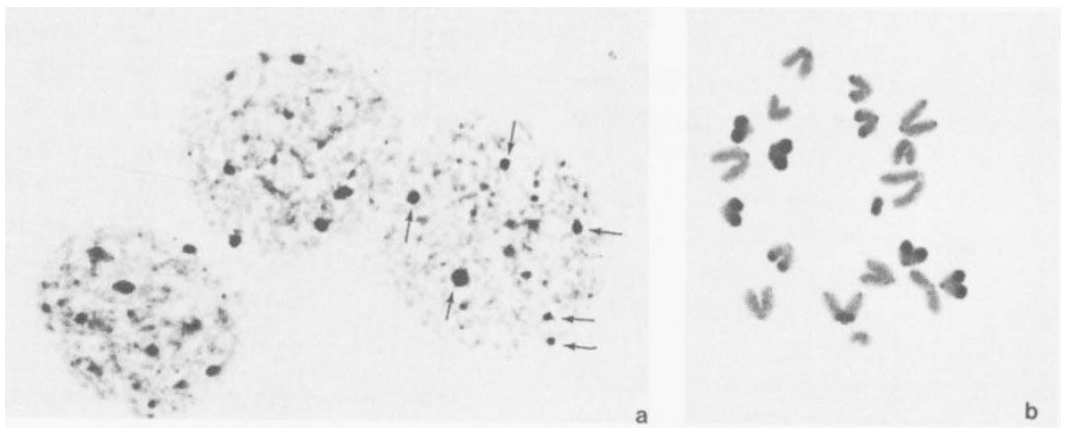

Figure 3 Early prophase (a) and a mitotic metaphase (b) of A. tornosi after digestion with Alu I and stained with Giemsa. Note that enzyme acts regardless of the degree of chromatin condensation. 

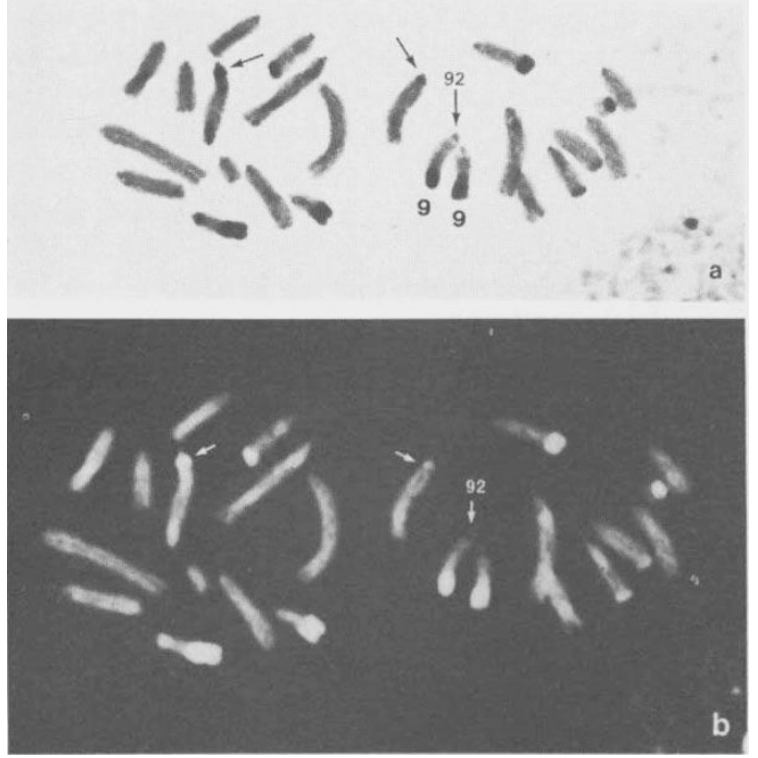

Figure 4 A metaphase plate of $A$. tornosi digested with Hinf $I$ and stained with Giemsa (a) and Acridine Orange (b). Note unstained gaps in the band 92. Arrows indicate heterochromatin associated with NORs in chromosome $\mathbf{M}_{3}$. base cutters are more efficient than 6 base cutters in cleaving and removing DNA from fixed chromosomes (Miller et al., 1983). In this context, it is noteworthy that Hind III (target = A $\downarrow$ AGCTT) was found incapable of producing appreciable logitudinal differentiation in fixed chromosomes of $\boldsymbol{A}$. tornosi, thus confirming that DNA extraction is difficult when chromosomes are digested with 6 base cutters. On the contrary, Alu I (target= AG $\downarrow C T)$, Hae III (target $=G G \downarrow C C$ ) and Hinf I (target $=$ G $\downarrow$ AATC) produced clearcut metaphase differentiation in metaphase chromosomes of $\boldsymbol{A}$. tornosi, thus confirming that $4-5$ base cutters are capable, with some exceptions (see Miller et al., 1983), to cleave and remove the DNA selectively from fixed chromosomes.

In situ digestion with certain REs, followed by staining with DNA-specific dyes, is proving useful for studying the organisation of polytene chromosomes (Mezzanotte, 1986) and meiotic chromosomes (Gosálvez, in preparation), as well as providing information on the DNA base composition of particular chromosomal areas (e.g., heterochromatin sensu lato) in mammals, rodents and diptera (Mezzanotte et al., 1983(a)-(b); Miller
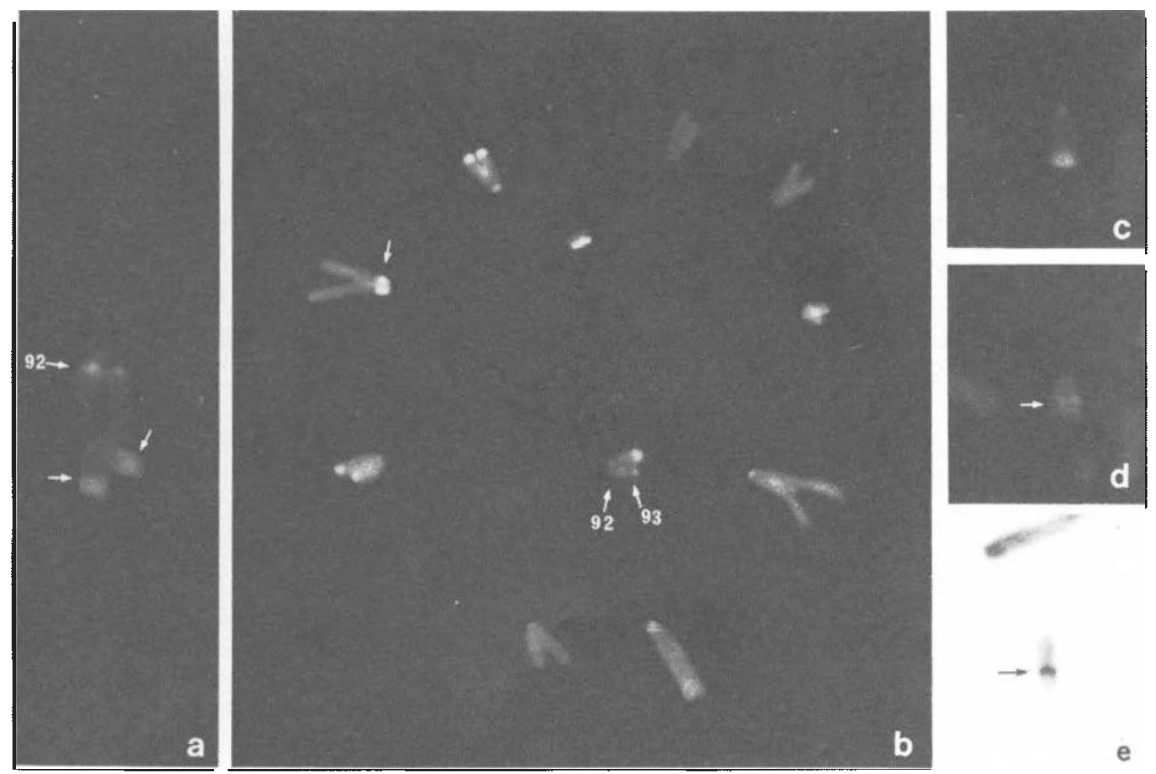

Figure 5 (a) Selected megameric bivalent $\left(\mathrm{M}_{9}\right)$ showing positive $\mathrm{CMA}_{3}$ staining in C-band 92 and heterochromatin associated with NORs (arrows). (b) Metaphase II of $A$. tornosi stained with DA/DAPI. Half bivalent $\mathbf{M}_{3}$ is arrowed to show the heterochromatin associated to the NOR. Note that C-bands 92 and 93 of the megameric chromosome are negative (half bivalent which is heterozygous for a distal DA/DAPI+ segment). (c)-(e) Selected $\mathrm{S}_{10}$ mitotic chromosome. (c) DA/DAPI+ fluorescence in the telomere and in the pericentromeric band. (d) $\mathrm{CMA}_{3}$ negative fluorescence in DA/DAPI+ regions. Arrow indicates two small interstitial dots which are $\mathrm{CMA}_{3}+$. (e) Hae III digestion. Note that DA/DAPI+ regions are cleaved to the same extent as euchromatin, but $\mathrm{CMA}_{3}+$ region is unaffected by that enzyme (arrow). 
et al., 1983; Mezzanotte and Ferrucci, 1984; Bianchi et al., 1985; Mezzanotte et al., 1985(a)-(b); De Stefano et al., 1986).

Constitutive heterochromatin often contains highly repeated DNAs which respond characteristically to RE attack depending on the presence or absence of the base sequence target in the highly repeated polynucleotide structure. The digestion of a given highly repeated DNA by a given RE may result in complete cleavage or preservation of such a DNA. Our results demonstrate considerable chromatin complexity in the karyotype of $A$. tornosi when treated with certain REs or tested with fluorochromes specific for $A / T$ or $G / C$ rich regions. The $\mathrm{C}$-bands usually considered as plain constitutive heterochromatin show large differences in their staining properties (heterochromatin heterogeneity) and some regions which are not C-banded can be recognised differentially. We have previously reported the existence of different types of heterochromatin in the closely-related species $A$. fusca using the metachromatic dye Acridine Orange for detecting different DNA conformations (Bella et al., 1986). These procedures allowed the differentiation of regions such as the centromeric heterochromatin, the heterochromatin associated with the NORs and the heterochromatin located in some telomeres which react uniformly after C-banding.

\section{Heterogeneity of constitutive heterochromatin}

It is possible to differentiate six different types of constitutive heterochromatin (C-bands) in addition to three different classes of non C-banded material in $A$. tornosi by considering its staining with specific ligands or after treatment with specific REs (table 1). In general the results obtained seem comparable to those reported in organisms other than $\boldsymbol{A}$. tornosi. For instance, some C-bands are digested by certain enzymes but unaffected by other enzymes. This augments previous observations demonstrating cytological heterogeneity within constitutive heterochromatin (Gatti et al., 1976; Schmid, 1980; Schmid et al., 1986; Schweizer, 1981). Nevertheless, some of our results seem apparently contradictory and merit detailed comments.

Let us begin with the effect of Hae III digestion on the AT-rich bands located at the telomeres. A DA-DAPI telomeric band (AT-rich) is located next to $\mathrm{CMA}_{3}$ interstitial band (GC-rich) on chromosome $\mathbf{M}_{10}$. Surprisingly, Hae III, whose restriction target is GG $\downarrow C C$, digests the DNA located at the telomere (i.e., AT-rich) but not the DNA of the interstitial $\mathrm{CMA}_{3}$ band (i.e., GC-rich). This suggests that $\mathrm{GG} \downarrow C C$ targets are interspersed, within the telomeric AT-rich DNA at the telomere to such an extent (i.e., base pair length frequency) that it permits DNA cleavage and removal. As it has been reported that the minimum length necessary for DNA removal from fixed chromosomes is $350 \mathrm{bp}$ (Mezzanotte, 1986), it seems reasonable to postulate the existence of at least one GG $\downarrow C C$ base sequence target spread among adjacent AT-rich DNA segments less than $350 \mathrm{bp}$ long. On this basis, we postulate the existence of specific base sequences that do not reflect AT or GC-richness, within GC or AT rich DNAs respectively. Such base sequences are necessary for enzyme cleavage, although not sufficient to determine bright fluorescence with DNA specific ligands.

The existence of alternate AT- and GC-rich stretches in specific chromosomal areas is also supported by what has been suggested by Schmid (1980) to explain the absence of quinacrine,

Table 1 Different types of chromatin in Arcyptera tornosi

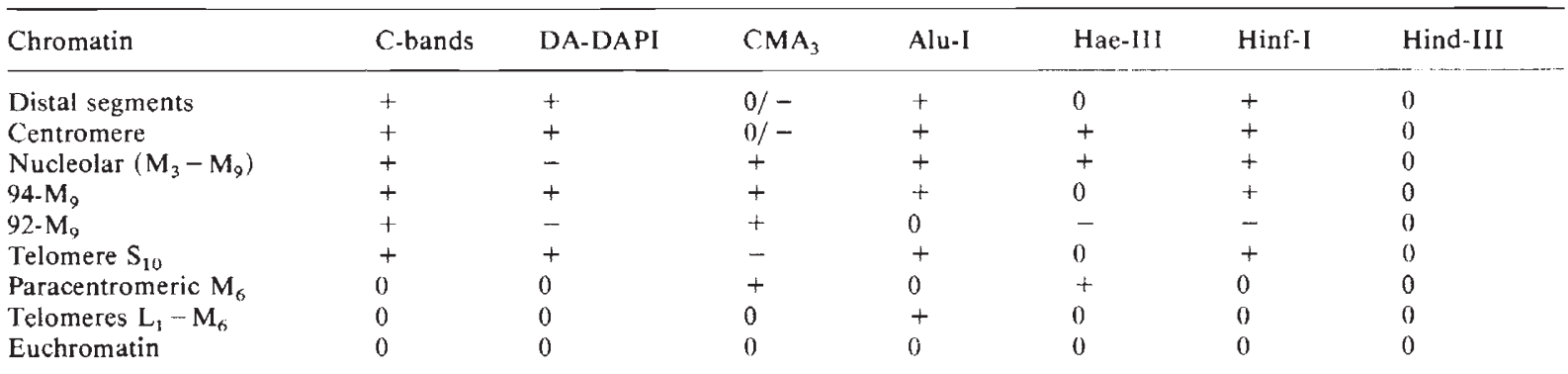

$+=$ Presence of differential staining (Band).

$-=$ Negative band.

$0=$ No bands. 
mithramycin and chromomycin $\mathrm{A}_{3}$ bright fluorescence in the heterochromatic regions of all anuran genera examined.

The possibility that chromatin compactness may represent a factor which permits or prohibits enzyme access to the DNA located at specific chromosomal regions is still open to discussion. Data presently available suggest that chromatin packing level should not play a major role in determining RE attack on chromosomal DNA. Data obtained in $A$. tornosi support this hypothesis. Thus interphase, early prophase and metaphase chromatin are digested in a similar fashion by the same RE and furthermore some C-bands (constitutive heterochromatin), such as C-band 92 of the megameric chromosome, are extensively digested by Hinf I or Hae III. This is further supported by the identical activity of restriction enzymes observed in different states of chromatin organisation such as $G_{1}$ and metaphase chromosomes (Bianchi et al., 1985) and also by the capability of Hinf I to extensively attack the paracentromeric C-band regions of human chromosomes 1, 9 and 16 which then appear as unstained gaps (Bianchi et al., 1985).

An apparent exception to this generalisation is the resistance of the heterochromatin associated with the active NORs $\left(\mathrm{CMA}_{3}+\right)$ in $A$. tornosi to all the enzymes we used. In this connection, we stress that NORs represent specially organised structures with particular responses to specific treatments (Hagele, 1979; Fox and Santos, 1985), and normally contain GC-rich DNA (Gall et al., 1969; Deumling and Greilhuber, 1982; Schmid, 1982; Schweizer et al., 1983). However some authors have found some RE to be able to cleave the DNA located at NORs in Drosophila melanogaster (Mezzanotte, 1986) and the Indian muntjac (Babu and Verma, 1986). Given that our results have been extended to other grasshopper species (Gosálvez, unpublished observation) we could argue that the DNA in these regions is impervious to some REs, possibly due to peculiar organisation of NORs in grasshoppers.

\section{Alu I/Hae III resistant chromatin}

Studies carried out on the chromosomes of different organisms show close correlation between $\mathrm{C}$-band positive heterochromatin and regions that fluoresce differentially with DNA specific dyes (John et al., 1985; Mayr et al., 1985; Schmid et al., 1986). However, in contrast there is not a complete correspondence between C-band positive heterochromatin and chromosomal areas resistant to cer- tain REs, since C-bands may or may not be attacked by a specific endonuclease in a number of organisms. It is true that an enzyme such as Alu I acts on the chromosomes of several species by removing DNA from all but a few chromosomal areas that are also C-banded (Mezzanotte et al., 1983(a), (b); Miller et al., 1983). However, Alu I bands are present not only in C-band regions but also in the telomeres of some A. tornosi chromosomes $\left(\mathrm{L}_{1}\right.$ to $\left.\mathrm{M}_{6}\right)$ that are neither $\mathrm{C}$-banded nor present bright staining with specific fluorochromes. In addition, the regions where Alu I bands and C-bands correspond show intense staining that involves more material after enzyme digestion than after C-banding. This fact, while confirming that C-bands do not necessarily coincide with RE bands, suggests that highly repeated DNAs, whose base sequence does not contain Alu I target, are localised in regions not belonging to the constitutive heterochromatin class.

Hae III is another enzyme incapable of cleaving specific, possibly repetitive DNA, that is located outside the constitutive heterochromatin (i.e., C-bands). On the other hand, this enzyme is capable of cleaving and removing the DNA localized at specific C-bands of the megameric chromosome, in particular C-band 92 that appears as a gap after Hae III treatment. The same enzyme, however, is incapable of cleaving the proximal and interstitial areas of $\mathrm{M}_{6}$ and $\mathrm{S}_{10}$ chromosomes. Interestingly, such regions are intensely stained by $\mathrm{CMA}_{3}$, thus revealing the presence of GC-rich DNA. It is noteworthy that the Hae III action on $\mathrm{CMA}_{3}$ positive regions is different in $A$. tornosi from mammals chromosomes. In fact, this enzyme produces G-like bands, interpreted in human chromosomes (Miller et al., 1983) as a consequence of extensive attack on the GC-rich DNA of Rbands (i.e., $\mathrm{CMA}_{3}$ bands) but it fails to digest $\mathrm{CMA}_{3}$ positive areas in $A$. tornosi chromosomes. This fact could be explained by invoking some peculiar structure that may inhibit enzyme access within nucleolar organiser regions (see above). Alternatively, it is possible that highly repeated DNA, which does not contain Hae III RE target, is present in such areas.

In conclusion, the possibility of detecting highly repetitive DNA sequences in regions others than C-bands clearly shows that the combined use of REs and standard cytogenetic techniques greatly increases the capacity for analysing the different types of chromatin organisation, and can help disentangle the problem of heterochromatin heterogeneity. This, in turn, provides new insights for analysing phenomena such as the equilocal 
distribution of similar classes of heterochromatin within chromosome complements.

Acknowledgements The authors wish to thank the Ministerio de Asuntos Exteriores de Espana and the Ministero degli Affari Esteri di Italia for partially supporting this work. This research was also partially supported by C.A.I.C.Y.T. N/r 2165-83 (Spain). Helpful discussion with Dr C. García de la Vega and Dr G. M. Hewitt is very much appreciated.

\section{REFERENCES}

BABU, A. AND VERMA, R. S. 1986. Expression of heterochromatin by restriction endonuclease treatment and dystamycin/dapi staining of Indian muntjac (Muntiacus muntjak) chromosomes. Cytogenet. Cell Genet., 41, 96-100.

BELLA, J. L., GARCIA DE LA VEGA, C., LOPEZ-FERNANDEZ, C. AND GOSALVEZ, J. 1986. Changes in acridine orange binding and its use in the characterisation of heterochromatic regions. Heredity, 57, 79-83.

BIANCHI, M.S., BIANCHI, N. O., PANTELIAS, G. E. AND WOLFF, S. 1985. The molecular mechanism and pattern of banding induced by restriction endonucleases in human chromosomes. Chromosoma, 91, 131-136.

DE STEFANO, G. F., ROMANO, E. AND FERRUCCI, L. 1986. The Alu I-induced bands in metaphase chromosomes of orangutan (Pongo pygmaeus). Hum. Genet., 72, 268-271.

DEUMLING, B. AND GREILHUBER, J. 1982. Characterisation of heterochromatin in different species of the Scilla siberica group (Liliaceae) by in situ hybridization of satellite DNA's and fluorochrome banding. Chromosoma, 84, 535-555.

FOX, D. P. AND SANTOS, J. L. 1985. N-bands and nucleolus expression in Schistocerca gregaria and Locusta migratoria. Heredity, 54, 333-341.

GALL, J. M., MACGREGOR, H. C. AND KIDSON, M. E. 1969. Gene amplification in the oocytes of Dystiscid water beetles. Chromosoma, 26, 169-187.

GATTI, M., PIMPINELli, S. AND SANTINI, G. 1976. Characterization of Drosophila heterochromatin. I. Staining and decondensation with Hoechst 33258 and Quinacrine. Chromosoma, 57, 351-375.

GOSALVEZ. J., LOPEZ-FERNANDEZ, C. AND MORALES. AGACINO, E. 1981. The chromosome system in three species of the genus Arcyptera (Orthoptera). I. C-banding, DNA content and NOR activity. Acrida, 10, 191-203.

HAGEI.E, K. 1979. Characterization of heterochromatin in Schistocerca gregaria by $\mathrm{C}$ and $\mathrm{N}$ banding methods. Chromosoma, 70, 239-250.

JOHN, B., K1NG, M., SCHWEIZER, D. AND MFNDELAK, M. 1985. Equilocality of heterochromatin distribution and heterochromatin heterogeneity in acridoid grasshoppers. Chromosoma, 91, 185-200.

JORGENSON, K. F., VAN DE SANDE, J. L. AND LIN, C. C. 1978. The use of base pair specific DNA binding agents as affinity labels for the study of mammalian chromosomes. Chromosoma, 68, 287-302.

KAELBlinG, M., MILler, D, A. ANI MILlER, O. J. 1984. Restriction enzyme banding of mouse metaphase chromosomes. Chromosoma, 90, 128-132.

KING, M. AND JOHN, B. 1980. Regularities and restrictions governing $\mathrm{C}$-band variations in acridoid grasshoppers. Chromosoma, 76, 123-150.

LOPEZ-FERNANDEZ, C., RUFAS, J. S. AND GOSALVEZ, J. 1982. Non-random segregation during anaphase II in an individual of Arcyptera tornosi (Orthoptera) heterozygous for three supernumerary heterochromatic segments. Genetica, 60, 37-39.

MACGREGOR, H. C. AND VARLEY, J. 1983. Working with Animal Chromosomes. John Wiley and Sons Ltd. New York.

MAYR, B., SCHWEIZER, I)., MENDELAK, M., KRUTZLER, J., SCHLEGER, W., KALAT, M. AND AUER, H. 1985. Levels of conservation and variation of heterochromatin and nucleolus organizers in the Bovidae. Can. J. of Genet. and Cytol, 27, 665-682.

MEZZANOTTE, R. 1986. The selective digestion of polytene and mitotic chromosomes of Drosophila melanogaster by the Alu I and Hae III restriction endonucleases. Chromosoma, $93,249-255$.

MEZZANOTTE, R., BIANC.HI, U., VANNI, R. AND FERRUCCI, L. 1983b. Chromatin organization and restriction endonuclease activity on human metaphase chromosomes. Cytogenet. Cell. Genet., 36, 562-566.

MEZZANOTTE, R. AND FERRUCCI, L. 1984. Alterations induced in mouse chromosomes by restriction endonucleases. Genetica, 64, 123-128.

MLZZANOTTE, R., FERRUCCI, L., VANNI, R. AND BIANCHI, U. 1983a. Selective digestion of human metaphase chromosomes by Alu I restriction endonucleases. J. Histochem. Cytochem., 32, 553-556.

MEZZANOTTE, R., FERRUCCI, L., VANNI, R. AND SUMNER, A. T. $1985 \mathrm{~b}$. Some factors affecting the action of restriction endonucleases on human metaphase chromosomes. Exp. Cell. Res., 161, 247-253.

MI:ZZANOTTE, R., MANCONI, P. E., ROZZO, C., ENNAS, M. G. AND FERRUCCI, L. 1985a. The banding pattern produced by restriction endonucleases in mouse chromosomes. Bas. Appl. Histochem., 29, 115-120.

MILlER, D. A., CHOI, J.C. AND MILLER, O. J. 1983. Chromosome localization of highly repetitive human DNAs and amplified ribosomal DNA with restriction enzymes Science, 219, 395-397.

SCHMID, M. 1980. Chromosome banding in Amphibia. IV. Differentiation of $\mathrm{GC}$ - and AT-rich chromosome regions in Anura. Chromosoma, 77, 83-103.

SCHMID, M. 1982. Chromosome banding in amphibia. VII. Analysis of the structure and variability of NORs in Anura. Chromosoma, 87, 327-344.

SCHMID, M., HAAF, T.. OTT, G., SCHERES, J. M. J. C. AND WENSING, J. A. B. 1986. Heterochromatin in the chromosomes of the gorilla: characterization with distamycin A/DAPI, D287/170, chromomycin $A_{3}$, quinacrine, and 5-azazytidine. Cytogenet. Cell Genet., 41, 71-82.

SCHWEIZER, D. 1976. Reverse fluorescent chromosome banding with Chromomicin and DAPI. Chromosoma, 58, $307-$ 324.

SC:HWEIZER, D. 1980. Simultaneous fluorescent staining of $\mathbf{R}$ bands specific heterochromatic regions (DA-DAPI bands) in human chromosomes. Cytogenet. Cell Genet, 27, 190193.

SCHWEIZER, 1). 1981. Counterstaining enhanced chromosome banding. Hum. Genet., 57, 1-14.

SCHWEIZER, D., MENDFIAK, M., WHITE, M. J. D. AND CONTRERAS, N. 1983. Cytogenetics of the parthenogenetic grasshopper Warramaba virgo and its bisexual relatives. $\mathrm{X}$. Patterns of fiuorescent banding. Chromosoma, 88, 227236.

SUMNER, A. T. 1972. A simple technique for demonstrating centromeric heterochromatin. Exp. Cell. Res., 75, 304-306.

TORRE, J. DE LA, LOPEZ-FER NANIJEZ, C., NICHOLS, R. AND (BOSALVEZ, J. 1986. Heterochromatin readjusting chiasma distribution in two species of the genus Arcyptera: the effect among individuals and populations. Heredity, 56, $177-184$ 